\title{
CONTRIBUIÇÕES DA TERAPIA COGNITIVO-COMPORTAMENTAL PARA O ENFRENTAMENTO E SUPERAÇÃO DO MEDO DE DIRIGIR
}

\author{
CONTRIBUTIONS OF COGNITIVE-BEHAVIORAL THERAPY FOR COPING AND \\ OVERCOMING THE FEAR OF DRIVING
}

\begin{abstract}
Mateus Alves Ferreira ${ }^{1}$
RESUMO: O presente artigo se constitui um estudo bibliográfico acerca do medo de dirigir. Como forma de atender aos objetivos desta pesquisa, esse trabalho investigou as técnicas da Psicologia, mais especificamente da Terapia Cognitiva Comportamental, com pessoas que apresentam medo na condução de um veículo. Inicialmente, este trabalho abordou os aspectos emocionais e psicológicos, relacionados ao medo e à fobia, bem como a conceituação e caracterização de ambos os termos. Em seguida, discorreu-se sobre o medo de dirigir, apontando as causas e motivações que levam uma pessoa a apresentar aversão pela prática veicular. E por último, discutiram-se as técnicas psicológicas que auxiliam no enfrentamento e superação do medo de dirigir. Com base no estudo apresentado, constatou-se o quanto a TCC (Terapia Cognitivo Comportamental) mostra-se uma alternativa eficaz no tratamento do medo de dirigir, à medida que esta modalidade de terapia apresenta recursos psicológicos, que ajudam o condutor a compreender a origem do seu medo, a resignificar os elementos relacionados à situação do trânsito, como também, conhecer e aplicar as técnicas que auxiliam na superação do medo de dirigir.
\end{abstract}

Palavras-chave: Dirigir. Medo. Psicologia. Terapia.

ABSTRACT: This article is a bibliographic study about the fear of driving. As way to meet the objectives of this research, this work investigated the techniques of Psychology, more specifically of Cognitive Behavioral Therapy, with people who are afraid when driving a vehicle. Initially, this work addressed the emotional and psychological aspects, related to fear and phobia, as well as the conceptualization and characterization of both terms. Then, the fear of driving was discussed, pointing out the causes and motivations that lead a person to show aversion to vehicular practice. Finally, psychological techniques that help in coping and overcoming fear of driving were discussed. Based on the study presented, it was found how much CBT (Cognitive Behavioral Therapy) is an effective alternative in the treatment of fear of driving, as this type of therapy presents psychological resources, which help the driver to understand the origin of their fear, to reframe the elements related to the traffic situation, as well as to know and apply the techniques that help to overcome the fear of driving.

Keywords: Driving. Fear. Psychology. Therapy.

\footnotetext{
${ }^{1}$ Graduado em Psicologia pela Pontifícia Universidade Católica de Minas Gerais. Psicólogo atuante nas áreas clínica e de avaliação psicológica no contexto do trânsito. Especialista em Psicologia do Trânsito e Neuropsicologia.E-mail: maf_2opsico@hotmail.com.
} 


\section{INTRODUÇÃO}

A ação de conduzir um veículo automotor tem se tornado não só comum, mas também uma necessidade atualmente, uma vez que este comportamento auxilia as pessoas nas suas atividades diárias, possibilita a mobilidade e oferece maior comodidade no deslocamento de um lugar ao outro. Entretanto, algumas pessoas não conseguem alcançar essa autonomia e independência no trânsito, devido a um problema que acomete pessoas no mundo todo, que é o medo de dirigir, foco de abordagem da presente pesquisa.

O medo de dirigir se caracteriza por ser uma reação emocional expressado diante da prática veicular, cuja situação é interpretada pelo indivíduo como sendo ameaçadora e aversiva. (HAYDU et. al., 2016).

A escolha do tema se deu a partir do interesse pessoal e subjetivo do pesquisador, em investigar as questões emocionais e psicológicas relacionadas ao medo de dirigir, logo, o objeto de estudo do presente trabalho é importante, vez que possibilita tecer discussões, ampliar o campo de visão e proporcionar o desenvolvimento de mais pesquisas em torno da temática em questão.

A metodologia utilizada para elaboração do presente artigo foi a pesquisa bibliográfica, cuja

modalidade, "é desenvolvida com base em material já elaborado, constituído principalmente de livros e artigos científicos." (GIL, 200o, p. 44).

Para um melhor entendimento acerca da presente pesquisa, esse trabalho foi estruturado em subtemas, nos quais serão abordados o conceito e a caracterização do medo e da fobia, os aspectos conceituais e motivacionais do medo de dirigir e, a posteriori, as técnicas apresentadas pela terapia cognitiva comportamental, para o enfrentamento e superação do medo de conduzir veículos automotores.

\section{REVISÃO DA LITERATURA 2.I O MEDO E A FOBIA: SIGNIFICADOS E DISTINÇÕES}

Falar do medo implica, necessariamente, discorrer acerca da emoção, cuja nomenclatura é definida como "uma resposta biológica com função adaptativa no processo de evolução da nossa espécie." (PRADO; BRESSAN, 2016, p. I04). Partindo de tal consideração, pode-se afirmar que a emoção diz respeito ao conjunto de reações que o organismo expressa diante de determinadas situações, na tentativa de um ajustamento frente a algum desafio. 
Desta forma, o medo é compreendido como uma emoção apresentada diante de alguma situação que represente algum perigo eminente para o indivíduo, funcionando, neste sentido, como um mecanismo de defesa que ao tempo que protege o indivíduo de sofrer algum dano, pode o impedir de realizar e de desenvolver determinadas atividades. (SCHOEN; VITALLE, 20I2).

Embora o medo seja percebido como uma emoção incômoda pelo indivíduo, os autores Prado e Bressan (2016) parafraseiam a ideia de Schoen e Vitalle, ao afirmarem que a referida emoção é natural e está presente em todos os seres vivos, podendo auxiliar, "a perceber e analisar sentimento; utilizar a compreensão desses sentimentos para organizar nossos pensamentos, compreender as relações entre as emoções e suas possíveis consequências". (PRADO; BRESSAN, 2016, p. 104).

Assim colocado, permite afirmar que, por mais que o medo seja desagradável de ser sentido, torna-se necessário, pois, auxilia o indivíduo a identificar e nomear suas sensações e sentimentos, consequentemente, viabiliza a criação de mecanismos para lidar e agir em situações que representam algum perigo ou risco à sua subsistência.

Schoen e Vitalle (2012) pontuam que o medo, em determinados momentos e dependendo do grau de intensidade, pode ser considerado comum, porém quando este medo toma uma dimensão maior, pode ser prejudicial para o indivíduo, chegando ao ponto de incapacitá-lo na realização de alguma atividade, tendo em vista que a pessoa passa a evitar determinadas situações, para não entrar em contato com o objeto que lhe gera ansiedade e incômodo, o que não é saudável do ponto de vista comportamental, uma vez que coloca o indivíduo em situação de incapacidade, refletindo negativamente em sua autoestima, independência, autonomia e posicionamento.

Embora os termos "medo" e "fobia" pareçam remeter ao mesmo significado, estas palavras possuem algumas peculiaridades, uma vez que o medo representa uma resposta emocional frente a uma situação de perigo, a fobia, um medo que foge ao controle do indivíduo, o qual ocorre intensamente e avassaladora, levando o indivíduo a apresentar comportamento de fuga diante de situações e objeto fóbicos. (MARQUES; GRADVOHL; MAIA, 2oIo).

Os autores Mognon, Santos e Martins (2017), vão ao encontro das ideias de Marques, Gradvohl e Maia, acerca da fobia, ao elencarem algumas características próprias desta reação, ressaltando que:

[...] quando se torna exagerado em relação a uma determinada situação, torna-se um transtorno de ansiedade denominado de fobia específica. Dentre os critérios diagnósticos, são mencionados: o medo acentuado e persistente diante da presença ou antecipação do estímulo fóbico; medo desproporcional ao do contexto real, persistência do sintoma por mais de seis meses e, por fim, o fato de ser a causa de prejuízo social e ocupacional. (MOGNON; SANTOS; MARTINS, 2017, p. 86). 
Desta forma compreende-se que a fobia é uma reação emocional apresentada pelo indivíduo estando ou até mesmo se imaginando em determinada situação (ex: trânsito, exposição ao público, socialização, dentre outros), a qual ocorre com uma frequência maior e desequilibradamente, gerando, desta forma, desconforto e comprometimento nas demais áreas de sua vida (profissional, pessoal, sentimental e relacional). (HAYDU et. al., 2016).

Ainda sobre as características da fobia, os autores Lopes, Carvalho e Barbosa (2014), pontuam que por mais que esta reação seja intensa e percebida conscientemente por quem a sente, ela é incontrolável, chegando ao ponto de bloquear a capacidade cognitiva do indivíduo e gerar distorções acerca dos elementos de uma determinada situação (trânsito, falar em público, socialização. dentre outros).

Para exemplificar e ampliar a discussão acerca do medo de dirigir, foco de estudo do presente trabalho, serão apresentados no tópico a seguir os aspectos conceituais, motivacionais e as características apresentadas por quem sofre deste mal-estar no trânsito.

\subsection{O MEDO DE DIRIGIR: ASPECTOS CONCEITUAIS E MOTIVACIONAIS}

O medo de dirigir é um problema que acomete pessoas do mundo todo, apresentando uma "taxa entre $7 \%$ e $8 \%$, sendo a maioria das pessoas do sexo feminino." (CANTINI; RIBEIRO; ANDRADE; PEREIRA; NARDI; SILVA, 2013, p. 125).

Contextualizando o surgimento dos estudos acerca do medo de dirigir, os autores, Taylor et al., citados por Mognon, Santos e Martins (2017), afirmam que a compreensão clínica da referida temática se deu apenas no final dos anos 70 e foi se expandindo com a realização e a ampliação de pesquisas científicas, relativas ao medo de dirigir. Dessa forma, os estudos iniciais alusivos ao medo, na prática veicular, foram voltados para uma abordagem mais específica, na qual buscou investigar os impactos psicológicos gerados em pessoas envolvidas em acidente de trânsito, pelas quais se tornou possível constatar que o medo de dirigir estava intimamente relacionado a experiências traumáticas e por vezes trágicas no contexto do tráfego.

O medo de conduzir veículo automotor é um problema universal, que pode apresentar oscilações entre níveis mais brandos como uma resistência por dirigir, até níveis mais pesados como uma recusa total pela prática veicular, levando o indivíduo a experienciar sensações de ansiedade (tremor, suor, taquicardia, respiração ofegante) e respostas de esquiva, ou seja, as pessoas que sofrem 
deste problema passam a evitar o contato com o veículo e/ou com qualquer elemento que esteja associado a uma situação de trânsito. (HAYDU et. al. 2016).

Mognon e colaboradores (2017) ressaltam que diante de situações novas e desconhecidas pelo indivíduo, o medo e a ansiedade são reações naturais, mas quando as referidas sensações persistem em acontecer, mesmo quando a pessoa já adquiriu conhecimentos acerca da prática veicular, pode se tornar um fator prejudicial ao bom desempenho do indivíduo no trânsito.

Condutores e candidatos à habilitação, que expressam medo de dirigir, podem apresentar algumas características peculiares, estando estas relacionadas ao "receio de errar, de ser criticado, de perder o controle do veículo, de sofrer um acidente, de atropelar um pedestre e de se machucar." (TAYLOR, et. al. apud MOGNON, SANTOS; MARTINS, 2017, p. 86).

Sobre o padrão de perfeccionismo, Corassa, citado por Silva e Trenhago (2014), afirma que este aspecto psicológico reflete negativamente no desenvolvimento do indivíduo no trânsito, tendo em vista que, quem apresenta este tipo de característica tem um nível de cobrança muito alto consigo mesmo e expressa grande dificuldade para lidar com críticas e julgamentos dos outros. Logo, o incômodo gerado pela sensação de ser julgado por terceiros, pode fazer com que o indivíduo represente o trânsito como um contexto desagradável.

Antes de discorrer acerca dos motivos relacionados ao medo de dirigir, é importante frisar que na literatura consultada os estudos foram voltados, na maioria das vezes, para o público feminino, tendo em vista que, para o público masculino é mais difícil reconhecer e assumir tal dificuldade devido às exigências sociais e até mesmo por questões culturais, as quais concebem o ser "homem" como sendo viril, corajoso e destemido de qualquer desafio. (BARP; MAHAL, 2013).

Corassa citado por Silva e Trenhago (2014), pontua que em uma análise mais ampla e abrangente é válido pensar que o medo de conduzir veículos não está, relacionado apenas a fatores psicológicos (ansiedade, insegurança, estresse pós-traumático, etc.), mas também às experiências de vida, influências sociais e culturais de cada pessoa.

Observando os motivos que levam uma pessoa a apresentar aversão pela condução de veículos, é possível destacar alguns fatores, sendo eles:

[...] a ausência de familiaridade com o carro, pois quando se conduz, são necessárias várias habilidades, como, ter noção de espaço para poder estacionar e não deixar o carro desligar. É natural que os recém-habilitados cometam essas falhas, em que se espera que com o tempo e a prática o condutor esteja mais adaptado com essas novas situações e não cometa mais esses erros. O segundo é o receio de errar e de receber críticas. $O$ condutor tem a sensação que todos estão olhando e avaliando os erros que cometeu, afetando sua autoestima. Esses dois fatores associados fazem os 
condutores iniciantes não quererem dirigir para evitar estas situações. (CORASSA, apud BARP; MAHL, 2013, p. 40).

Considerando as proposições apresentadas pelos referidos autores, no parágrafo anterior, é possível inferir a ideia de que o medo de dirigir, observado, principalmente em motoristas principiantes, pode estar associado a questões de imperícia, como também a fatores psicológicos e/ou sociais, à medida que o condutor se sente observado e apresenta receio de falhar enquanto dirige e de receber julgamentos ou ser percebido como uma pessoa incapaz, pelas outras pessoas.

Concordando com a ideia de Cantini e colaboradores, os autores Barp e Mahl (2013) citam os fatores relacionados ao medo de conduzir um veículo automotor, destacando o envolvimento de uma pessoa com acidentes automobilísticos, experiências negativas no trânsito, o comodismo, a ausência de estímulo, a conduta do instrutor, fatores psicológicos, dentre outros.

O acidente de trânsito é uma experiência que pode acarretar prejuízo tanto do ponto de vista físico (lesões, fraturas, perda dos membros do corpo, entre outros), financeiro (reparo de estragos feitos no veículo, manutenção, entre outros gastos) como também psicológico (traumas, estresse, entre outros). A pessoa que sofre um acidente ou até mesmo o presencia, pode passar a significar o trânsito, e todos os elementos a este, relacionados, como um local ameaçador, desta forma, a pessoa pode desenvolver medo de dirigir, viajar de carro ou de ônibus, ou até mesmo pelo simples fato de se ver no contexto do tráfego.

Em relação ao comodismo pode-se afirmar que o medo de dirigir faz com que as pessoas coloquem limites às suas capacidades e consequentemente inviabiliza a busca por uma independência no trânsito, levando-as a dependerem de outras pessoas para se deslocarem de um lugar ao outro.

A falta de um incentivo/ou estímulo no trânsito também foi apontada como um fator que contribui para o desenvolvimento e a intensificação do medo de dirigir, conforme analisam Cantini, et. al., (2013), à medida que o incentivo funciona como um fator externo, com a função de encorajar a pessoa a vencer seus medos e a desmistificar crenças equivocadas (trânsito como local de tragédia), a respeito do tráfego, ao passo que a ausência deste estímulo pode colaborar para que os medos e as crenças errôneas se acentuem ainda mais, impossibilitando o indivíduo de exercer a prática veicular.

A conduta do instrutor pode influenciar tanto positiva como negativamente no desempenho do condutor no trânsito, tendo em vista que em alguns casos este, por impaciência e até mesmo desconhecimento, acaba não instruindo o candidato adequadamente, fazendo com que este se sinta menos interessado, tenha receios e se perceba como alguém incapaz. 
Em relação aos fatores psicológicos, Corassa citado por Barp e Mahl (2013) considera que a insegurança, a baixa autoestima e a subestimação das potencialidades podem contribuir para o desenvolvimento e manutenção do medo de dirigir, à medida que o indivíduo passa a interiorizar esta percepção equivocada (incapacidade) e consequentemente perde as oportunidades e até mesmo omite alguma atividade por acreditar que não vai conseguir.

Concernente aos elementos do trânsito têm-se as vias, os pedestres, as placas, os veículos, dentre outros. Porém um objeto que é importante ser lembrado e que por vez é percebido pelas pessoas que apresentam medo em dirigir como algo aversivo, é o carro, elemento do trânsito, o qual pode ser encarado por alguém acometido por esse mal estar, como um instrumento capaz de fazer estragos e até mesmo tragédias, ao invés de ser pensado como um recurso que facilitará a sua locomoção. (SILVA; TRENHAGO, 2014).

Como forma de apontar caminhos para tratar e superar o medo de dirigir, o próximo tópico discorrerá acerca das técnicas psicológicas, mais especificamente da Terapia Cognitiva Comportamental, que auxiliam a pessoa que apresenta aversão ao volante, a vencer seus medos/fantasmas e a ter um bom desempenho no trânsito.

\subsection{TÉCNICAS PSICOLÓGICAS NO ENFRENTAMENTO DO MEDO DE DIRIGIR}

O medo/fobia de dirigir é um transtorno psicológico que pode ser superado mediante a utilização de técnicas apropriadas, as quais auxiliam a pessoa que sofre desse mal-estar no trânsito a ressignifica os elementos a estes relacionados, a controlar suas reações e a criar mecanismos de enfrentamento diante de situações desafiantes e incômodas.

Antes de traçar um plano de tratamento para o problema em questão, primeiramente, é importante conhecer o histórico de vida de quem apresenta aversão ao volante, de modo a obter informações que auxiliam na compreensão das " [...] situações desencadeantes de sintomas e grau de interferência e prejuízo na vida do indivíduo; fatores ambientais e influência familiar; e habilidades sociais pré-existentes”. (ITO; ROSO; TIWARI; KENDALL; ASBAHR, 2008, p. 97).

Quando a pessoa apresenta aversão por dirigir, "há um estado de apreensão (ansiedade) significativo". (CALÓ, 2005, p. oI). Dessa forma, Ito et. al. (2008), afirmam que uma das técnicas que pode ser utilizada para auxiliar a pessoa a reduzir os níveis de ansiedade, é o manejo do estresse e relaxamento, cuja prática consiste na identificação de fatores ou situações que geram estresse e ansiedade no indivíduo e, a partir desta identificação, permite-se utilizar exercícios de respiração 
como forma de controlar e não intensificar a ansiedade. Inicialmente esta técnica pode ser usada no próprio consultório com o cliente, no qual o terapeuta o levará a pensar nas situações relacionadas ao trânsito, a perceber seus sintomas e a partir daí, aplicar este recurso terapêutico para controlar suas reações diante do volante ou até mesmo ao se imaginar em qualquer situação relacionada ao tráfego.

Considerando que a pessoa com fobia de dirigir apresenta algumas distorções, ou seja, pensamentos negativo-equivocados em relação aos elementos do trânsito, principalmente do veículo, tem-se a reestruturação cognitiva, uma técnica da Terapia Cognitivo-Comportamental cuja função se baseia em “[...] reestruturar e corrigir esses pensamentos distorcidos e colaborativamente desenvolver soluções pragmáticas para produzir mudança e melhorar transtornos emocionais." (KNAPP; BECK, 2008, p. 57). Mediante a referida técnica, o cliente é orientado pelo terapeuta a questionar e avaliar a veracidade de seus pensamentos, a dar um novo sentido aos elementos relacionados ao trânsito e a desenvolver pensamentos positivos, os quais possibilitem que o fóbico aja de forma mais assertiva e autêntica diante da condução veicular.

Partindo do pressuposto de que uma das formas mais eficaz de superação do medo é o enfrentamento, tem-se a técnica da exposição, cuja abordagem terapêutica fundamenta-se na ideia de que:

Paciente e terapeuta identificam todas as situações consideradas causadoras de ansiedade. Uma vez listadas, as situações são classificadas hierarquicamente de acordo com o grau de ansiedade que geram, começando com situações que causam menos ansiedade, até as mais temidas de serem enfrentadas. O paciente é orientado, então, a enfrentar as situações que estão no início desta lista e exercitarse repetidamente, até que sua ansiedade diminua (fenômeno denominado habituação). A exposição a cada uma das situações deve ser sistemática, ou seja, muito frequente, e por tempo prolongado para que a habituação possa acontecer. (ITO; ROSO; TIWARI; KENDALL; ASBAHR, 2008, p. 98).

Com base nas proposições do parágrafo anterior, é valido ressaltar que o paciente deve entrar em contato com o elemento/situação que lhe gera ansiedade, porém esta aproximação não pode ocorrer imediatamente, e, sim, de maneira gradual, à medida que o paciente desenvolve recursos para lidar e controlar suas reações ansiógenas e expressa coragem para enfrentar as situações, que para ele, são ameaçadoras. Supondo que o paciente tenha aversão por dirigir, mostra-se necessário que o terapeuta oriente e o encoraja a enfrentar seus medos, expondo o mesmo a objetos/elementos que lembram o trânsito ou até mesmo em contato com o carro, até chegar o momento em que a pessoa fóbica se sinta menos incomodada e mais confiante para encarar a prática veicular.

A interação entre o humano com os recursos tecnológicos tem sido viabilizada por meio da expansão tecnológica. Assim como a tecnologia está presente nas diversas atividades do cotidiano 
do ser humano, ela também pode ser aplicada como um recurso terapêutico nos tratamentos das fobias, como exemplo destaca-se a terapia por meio da realidade virtual, a qual se caracteriza, segundo Costa, de Carvalho e Nardi citados por Haydu et. al. (2016) como uma técnica de exposição do paciente com a situação aversiva, porém mediada pelos meios virtuais. Os referidos autores pontuam que nesta modalidade o terapeuta pode controlar os cenários aos quais o paciente será exposto, reduzindo, desta forma, as interferências (de pessoas, veículos, entre outros) que podem ocorrer durante a exposição do paciente a uma situação real de trânsito.

Conforme analisam Barp e Mahl (2013), a psicoterapia é um recurso importante para auxiliar na superação do medo de dirigir, entretanto, para que o tratamento seja mais efetivo é importante associar a terapia a treinamentos/reciclagem veicular, para adquirir conhecimento e desenvolver habilidades inerentes ao contexto do tráfego.

\section{CONSIDERAÇÕES FINAIS}

O presente trabalho buscou analisar a questão do medo de dirigir enquanto um fenômeno psicossocial que afeta o desenvolvimento das habilidades sociais do indivíduo e reflete negativamente na imagem que o mesmo faz de si para realização de atividades desafiantes.

Evidencia-se, com base nesse estudo, que o medo é uma reação natural, presente em todo ser vivo, porém a falta desta reação pode ser prejudicial para o indivíduo, uma vez que o coloca em situação de risco e pode comprometer a sua integridade psíquica e física.

Antes de propor alguma forma de intervenção é importante conhecer os motivos que levaram a pessoa a apresentar aversão por dirigir, porém, é importante não só considerar o histórico de vida do paciente como também os recursos que o mesmo dispõe e a percepção que ele faz acerca dos elementos relacionados ao trânsito. Prender-se apenas ao histórico de vida do paciente é reduzir a compreensão acerca dos fatores relacionados ao medo de dirigir e desconsiderar o entendimento das causas de forma dinâmica e sistematizada.

Em relação às propostas de intervenção da Psicologia, verificou-se que essa área do conhecimento dispõe de recursos terapêuticos que auxiliam, significativamente, o indivíduo que apresenta aversão ao volante a encarar seus medos e a desenvolver mecanismos para lidar com as circunstâncias que lhe geram tensão e ansiedade. Além das intervenções anteriormente mencionadas, o trabalho apontou a importância de associar a aplicação das técnicas da Terapia Cognitivo-Comportamental à prática veicular, para adaptação e familiarização com as diversas situações do trânsito. 
Por meio da revisão bibliográfica, constatou-se a necessidade do desenvolvimento de mais pesquisas voltadas para a temática em questão, de modo a ampliar as discussões acerca do medo de dirigir e propiciar que novas intervenções sejam realizadas para superar esse mal-estar no trânsito.

\section{REFERÊNCIA}

BARP, Maristela; MAHL, Álvaro Cielo. Amaxofobia: um estudo sobre as caudas do medo de dirigir. Unoesc\&Ciência - ACBS, Joaçaba, v.4, n.I, p. 39-48, jan./jun, 2013. Disponível em: $<$ http://editora.unoesc.edu.br/index.php/acbs/article/view/2627/pdf $>$. Acesso em: 9 set. 2017.

CALÓ, Fábio Augusto. Medo de dirigir, ansiedade ao dirigir e fobia. 2005. Disponível em: $\langle$ http://www.inpaonline.com.br/artigos/voce/medo_de_dirigir.htm〉. Acesso em: 05/II/2017.

CANTINI, Jessye Almeida; RIBEIRO, Letícia; ANDRADE, Simone Maria Hazin Paes de, PEREIRA, Valeska Martinho; NARDI, Antonio Egídio; SILVA, Adriana Cardoso. Medo e evitação na direção de veículos: características de motoristas que nunca dirigiram após obtenção da carteira nacional de habilitação. Jornal Brasileiro de Psiquiatria, Rio de Janeiro, v.62, n. 2, abr/jun, 2013. Disponível em: <http://www.scielo.br/scielo.php?script=sci_arttext\&pid=Soo4720852013000200005>. Acesso em: 10 out. 2017.

Gil, Antônio Carlos. Como elaborar projetos de pesquisa - 4. ed. - São Paulo: Atlas, 2002.

HAYDU, Verônica Bender; PAULA, Mariana Beatriz de; ZACARIN, Marcela Roberta Jacyntho; SANTOS, Andressa dos; Borloti, Elizeu; FORNAZARI, Sílvia Aparecida. Terapia por meio de exposição à realidade virtual para medo e fobia de dirigir: uma revisão da literatura. Avances em Psicología Latinoamericana, Bogotá (Colômbia), v.34, n.I, p. 67-8I, 2016. Disponível em: >. Acesso em: 03 out. 2017.

ITO, Ligia M; ROSO, Miréia C; SHILPEE, Tiwari; KENDALL, Philip C; ASBAHR, Fernando R. Terapia cognitivo-comportamental da fobia social. Revista Brasileira Psiquiatria, São Paulo, v. 3o, p. 96-ıог, 2008. Disponível em: 〈http://www.scielo.br/scielo.php?script=sci_arttext\&pid=Sisı644462008000600oo7>. Acesso em: io out. 2017.

KNAPP, Paulo; BECK, Aaron T. Fundamentos, modelos conceituais, aplicações e pesquisa da terapia cognitiva. Revista Brasileira Psiquiatria, São Paulo, v.3o, supl. 2, p.54-64, 2008. Disponível em: 〈http://www.scielo.br/scielo.php?script=sci_arttext\&pid=Si516-444620080oo6oooo2〉. Acesso em Io nov. 2017.

LOPES, Catarina de Castro; CARVALHO, Sônia Cortinhas; BARBOSA, Maria Raquel. Tratamento de Fobia especifica por dessensibilização e reprocessamento por meio dos movimentos oculares. Revista Psicologia: Teoria e Prática, São Paulo, v. I6, n.I, p.31-42, jan/abr, 2014. Disponível em: < <http://pepsic.bvsalud.org/scielo.php?script=sci_arttext\&pid=Si516-36872014000100003>. Acesso em 05 out. 2017.

MARQUES, Karyne Barreto Gonçalves; GRADVOHL, Morgana Pontes Brasil; MAIA, Maria Cristina Germano. Medo e ansiedade prévios à consulta odontológica em crianças do município de 
Acaraú-CE. Revista Brasileira em Promoção da Saúde, Fortaleza, v. 23, n. 4, p. 358-367, out/dez, 2010. Disponível em: 〈http://periodicos.unifor.br/RBPS/article/view/2038/2332>. Acesso em or out. 2017.

MOGNON, Jocemara Ferreira; SANTOS, Acácia Aparecida Angeli dos; MARTINS, Salete Coelho. Avaliação e intervenção para o medo e a fobia de dirigir: revisão da literatura. Contextos Clínicos, v. Io, n.I, p. 85-9, janeiro/junho, 2017. Disponível em: $\langle$ http://revistas.unisinos.br/index.php/contextosclinicos/article/view/ctc.2017.101.07〉. Acesso em II out. 2017.

PRADO, Alessandra Lemes; BRESSAN, Rodrigo Affonseca. O estigma da mente: Transformando o medo em conhecimento. Rev. Psicopedagogia, v.33, n.Ioo, p. I03-109, 2016. Disponível em: $\langle$ http://pepsic.bvsalud.org/scielo.php?script=sci_abstract\&pid=So103-848620160oorooor2〉. Acesso em 20 out. 2017.

SCHOEN, Teresa Helena; VITALlE, Maria Sylvia S. Tenho medo de quê? Rev Paul Pediatr, São Paulo, v.30, n.I, p.72-78, 2012. Disponível em: 〈http://www.scielo.br/scielo.php?script=sci_arttext\&pid=So103-0582201200o100oIr $>$ Acesso em: 05 set. 2017 .

SILVA, Adriana M. Klein; TRENHAGO, Janinha. Mulheres com medo de dirigir: um olhar além das aparências. 2014. Monografia (Conclusão de curso) - Universidade do Oeste de Santa Catarina. Disponível em: 〈https://editora.unoesc.edu.br/index.php/siepe/article/view/5685/2985〉. Acesso em ro out. 2017. 